\title{
A CONJUNTURA DOS INSTRUMENTOS DA POLÍTICA ESTADUAL DE RECURSOS HÍDRICOS DO ESTADO DO RIO GRANDE DO SUL ${ }^{1}$
}

\author{
THE SITUATION OF LEGAL INSTRUMENTS IN THE STATE POLICY FOR \\ WATER RESOURCES IN RIO GRANDE DO SUL
}

\author{
LA COYUNTURA DE LOS INSTRUMENTOS DE LA POLÍTICA ESTADUAL DE \\ RECURSOS HÍDRICOS DEL ESTADO DEL RIO GRANDE DEL SUR
}

\author{
Mara Alini Meier - Universidade Federal de Santa Maria - Santa Maria - Rio Grande do Sul - Brasil \\ mara.alini@gmail.com
}

\begin{abstract}
Resumo
0 Rio Grande do Sul, mesmo sendo o estado brasileiro pioneiro na constituição da Legislação de Recursos Hídricos, ainda não consolidou seu Sistema de Recursos Hídricos nem implementou os instrumentos da legislação. Os entraves para isso são a falta de Agências de Região Hidrográfica, a não consolidação dos instrumentos de planejamento, base para os demais instrumentos, e a implementação precária dos instrumentos de gestão. Além disso, há necessidade iminente de desenvolver instrumento estratégico para informar a sociedade e mobilizá-la a participar ativamente dos processos de planejamento das bacias hidrográficas junto aos Comitês de Bacia Hidrográfica. Entre as perspectivas para o gerenciamento, tem-se necessidade de efetivar a Legislação de Recursos Hídricos, mediante a consolidação dos instrumentos de planejamento, de gestão e estratégico. Só assim é possível sanar os entraves apresentados para realmente proteger este bem precioso, a água.
\end{abstract}

Palavras-chave: recursos hídricos, legislação, planejamento, gerenciamento.

\begin{abstract}
Despite being a pioneer in establishing the Water Resources Law, the State of Rio Grande do Sul has not yet consolidated its own Water Resources System, neither has it implemented the legal instruments. The obstacles are the absence of Hidrographic Regional Agencies, the non-consolidation of planning tools, which are the basis for all other legal instruments and poor implementation of management tools. Besides of this, there is a perceived need to develop strategic tools to inform and mobilize society to actively participate in the planning processes of watersheds at the Watershed Committees. Among the management perspectives, there is the need for establishing the Water Resources Law, through the consolidation of planning, management and strategic tools. Only so will it be possible to solve the problems presented and really protect water, this precious resource.
\end{abstract}

Keywords: water resources, management, planning, management.

\section{Resumen}

El Estado del Rio Grande del Sur a pesar de ser pionero en La constitución de Recursos Hídricos, aún no ha consolidado su sistema de Recursos Hídricos y la implantación de los instrumentos de la legislación. Las trabas que se presentan son: La falta de las agéncias de Región Hidrográfica; de la consolidación de los instrumentos de planeamiento que son la base a los demás instrumentos; la implantación precaria de los instrumentos de gestión; y la necesidad inminente de desarrollar el instrumento estratégico, para que se informe y movilize la sociedad a participar activamente de los procesos de planeamiento de las Bacias Hidrográficas, junto a los Comités de Bacía Hidrográfica. Entre las perspectivas al gerenciamento hay: necesidad de efectuación de la Legislación de Recursos Hídricos con la finalidad de sanar las trabas presentadas, mediante la consolidación de los instrumentos de planeamiento, gestión y estratégicos a fin de qué se pueda realmente proteger este bien precioso, el água.

Palabras claves: recursos hídricos, legislación, planificación, gestión. 
Introdução

A água é um recurso precioso, pois é indispensável à vida de qualquer ser vivo, sendo utilizada em usos múltiplos. Ela vem, no entanto, sendo ameaçada pela degradação proveniente das ações indevidas do homem, o que acaba resultando em prejuízo para a própria humanidade e ameaçando a sobrevivência das espécies sobre a Terra. Nessa relação predatória que se desenvolve com o meio ambiente, observa-se que a principal consequência é a crise das águas que se vive atualmente, tanto na relação de qualidade quanto na de quantidade.

No Brasil, os recursos hídricos estão regulamentados pela Lei $\mathrm{n}^{\circ}$ 9.433/1997, e no estado do Rio Grande do Sul, pela Lei n ${ }^{\circ} 10.350 / 1994$. Ambas as legislações instituem, respectivamente, a Política Federal e a Estadual de Gerenciamento de Recursos Hídricos, responsáveis pela estruturação dos Sistemas Federal e Estadual de Recursos Hídricos, compostos por diferentes órgãos.

O Sistema Estadual de Recursos Hídricos (SERH) do Rio Grande do Sul é composto pelos seguintes órgãos: Conselho Estadual de Recursos Hídricos (CRH), Departamento Estadual de Recursos Hídricos (DRH), Agências de Região Hidrográfica (ARH), Fundação Estadual de Proteção Ambiental (Fepam) e Comitês de Bacia Hidrográfica (CBH). Esses órgãos são responsáveis pela implementação dos seguintes instrumentos: a) de planejamento: Plano Estadual de Recursos Hídricos e Plano de Bacia Hidrográfica e Enquadramento; b) de gestão: outorga e cobrança pelo uso da água; c) estratégico: Sistema de Informações sobre os Recursos Hídricos (Rio Grande do Sul, 1994).

Diante da crise das águas, tem-se a necessidade de discutir quais são as ações desenvolvidas nas bacias hidrográficas brasileiras pelas instâncias competentes para realizar uma gestão eficaz dos recursos hídricos. Essa questão pode ser analisada mediante a implementação dos instrumentos previstos na legislação vigente, tidos como indicadores da gestão, pois devem proporcionar a implantação da Política de Recursos Hídricos tanto no nível nacional quanto no estadual. Ou seja, somente com os instrumentos implementados é que se pode verificar o grau de eficácia do sistema de gestão (Porto, M.; Porto, R., 2008).

A partir disso, tem-se como objetivo deste artigo avaliar quais instrumentos da legislação de recursos hídricos estão implementados no Rio 
Grande do Sul e quais se encontram em discussão, analisando a prática dos Comitês de Bacia Hidrográficas e dos demais órgãos do SERH. Com isso, podem-se compreender os principais entraves à consolidação dos instrumentos que possibilitam a proposição de alternativas a esse processo e contribui com a proteção dos recursos hídricos.

Caracterização da área de estudo: bacias hidrográficas

O estado do Rio Grande do Sul é dividido em três regiões hidrográficas (RH): a do Uruguai, a do Guaíba e a das Bacias Litorâneas. As RHs são divididas em bacias hidrográficas (BH), totalizando 25 no estado (Rio Grande do Sul, s.d.). Desse conjunto, 22 fazem parte do SERH, enquanto as três restantes compreendem as bacias de domínio da União, duas localizadas na RH do Uruguai (Quaraí e Negro) e uma na RH das Bacias Litorâneas (Mirim - São Gonçalo) (Rio Grande do Sul, 2008). A localização das RHs e dos CBHs podem ser mais bem visualizados na Figura 1.

Os primeiros $\mathrm{CBH}$ criados no estado foram os da $\mathrm{BH}$ dos rios Gravataí e dos Sinos, em 1980, sendo este último o primeiro comitê instituído em nível nacional (Victorino, 2007). O último CBH criado no estado foi o da BH do Mampituba.

\section{Plano Estadual de Recursos Hídricos}

O Plano Estadual de Recursos Hídricos (PERH) do Rio Grande do Sul está em fase de elaboração e tem como objetivos apresentar um panorama da situação em que se encontram os recursos hídricos e em cima disso traçar metas e estratégias. O PERH harmoniza em si os planos de $\mathrm{BH}$ e supre momentaneamente a ausência dos que ainda faltam, mas não os substitui. Sendo assim, os planos de BH devem subsidiar a elaboração do PERH.

A necessidade que impulsiona a implementação do PERH provém do entendimento que o Departamento de Recursos Hídricos (DRH) - órgão da Secretaria do Meio Ambiente responsável pela gestão da água no estado - possui sobre a importância do Plano na regulação da ocupação do espaço, compatibilizando desenvolvimento social e econômico de maneira sustentável, em consonância com a proteção do meio natural. Contemplando essas premissas, o PERH é um acordo a respeito do plane- 


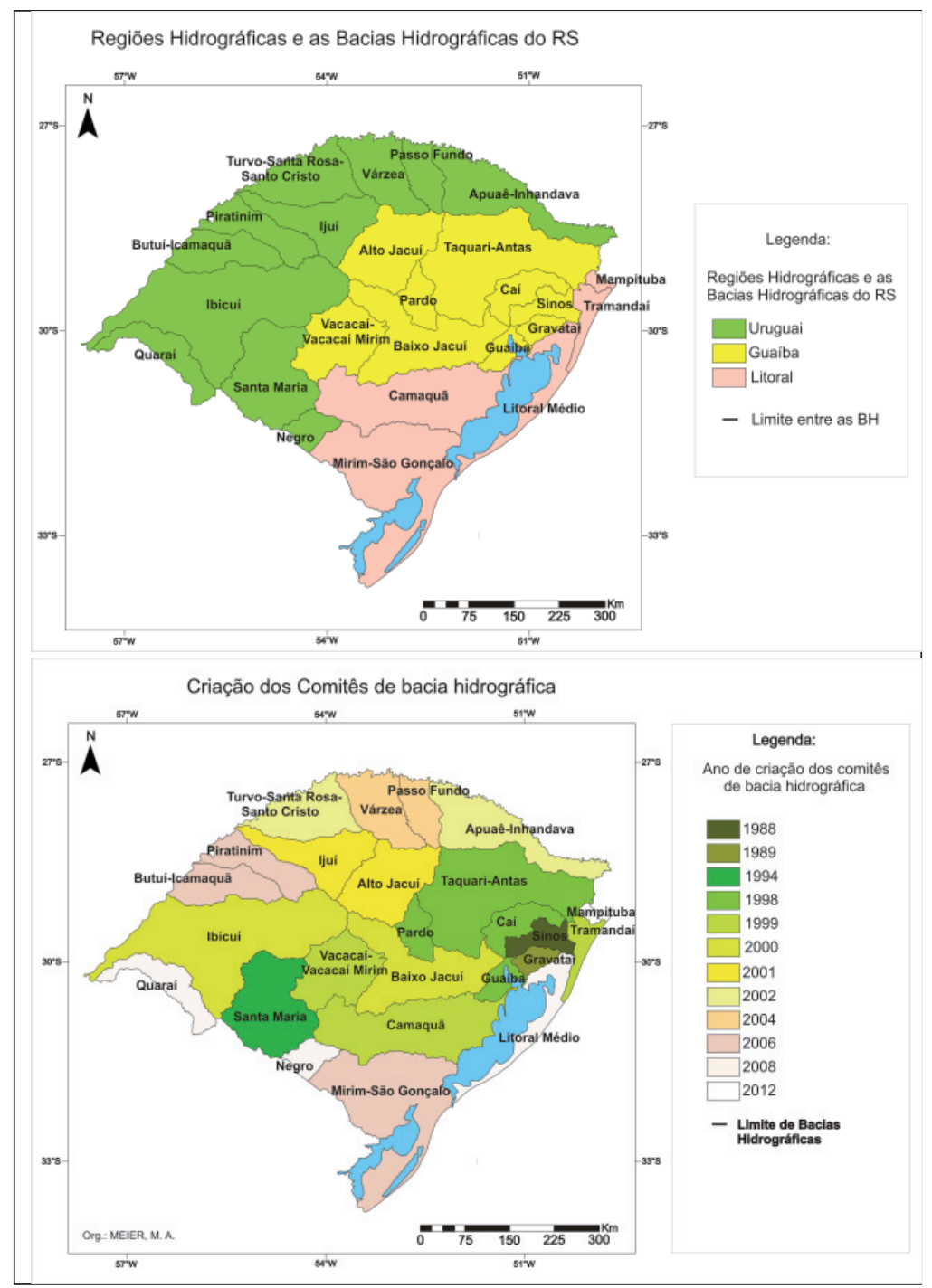

Figura 1 - As regiões hidrográficas e data de criação dos CBHs do Rio Grande do Sul Fonte: Rio Grande do Sul (s.d). 
jamento sustentado das BHs do estado, um instrumento estratégico que estabelece diretrizes gerais sobre os recursos hídricos. Por esse motivo, tem de ser elaborado de forma participativa, pois deve refletir os anseios, as necessidades e metas das populações das diversas BHs do estado, de forma a proporcionar crescimento econômico e social compatíveis com a preservação e o uso sustentável do meio ambiente (Paim, 2010).

O PERH começou a ser elaborado em 2006, mediante convênio entre o DRH e a Ecoplan Engenharia Ltda. Foram previstas quatro fases para a consolidação do plano: $1^{\mathrm{a}}$ ) diagnóstico das disponibilidades hídricas; $2^{\mathrm{a}}$ ) proposição de alternativas para compatibilizar disponibilidades e demandas hídricas; $3^{\mathrm{a}}$ ) criação do Plano Estadual de Recursos Hídricos; $4^{\mathrm{a}}$ ) elaboração do projeto de lei do Plano Estadual de Recursos Hídricos (Rio Grande do Sul, 2008).

A primeira e a segunda fase foram realizadas entre 2006 e 2007, e proporcionaram uma base de informações de suma relevância para o desenvolvimento das demais (Rio Grande do Sul, 2008). O PERH foi interrompido em 2007 e retomado no fim de 2010, quando foi reformulada a segunda fase. Atualmente a terceira fase está em processo de finalização e a última, em elaboração, segundo dados referentes ao primeiro semestre de 2013.

Observa-se que o PERH está avançando de maneira lenta no estado, mesmo havendo a consciência de que esse instrumento é crucial ao planejamento do uso das águas e para a implementação dos demais instrumentos - gestão e estratégico - no estado.

Pode-se destacar que as informações advindas do processo de desenvolvimento do PERH irão subsidiar a discussão da qualidade futura das águas com a população das BHs do estado. Com o Plano, será possível instituir a outorga de uso da água como instrumento de gestão, e não como mero registro cartorial, pois a outorga estará baseada em critérios e diretrizes oficiais, e em informações da $\mathrm{BH}$, contribuindo, assim, para que as metas futuras de qualidade propostas no enquadramento sejam atingidas. Com a outorga efetivada, será possível estabelecer a cobrança pelo uso da água, recursos que serão revertidos em ações estruturais e não estruturais, conforme detalhado no PERH. Além disso, as informações advindas do desenvolvimento do PERH irão alimentar o Sistema Estadual de Informações sobre os recursos hídricos, o qual irá retroalimentá-lo com informações necessárias para as suas revisões periódicas. 
Entre os entraves ao desenvolvimento do PERH, pode-se citar a falta dos planos de $\mathrm{BH},{ }^{2}$ pois são eles que fornecem as informações necessárias a esse processo. Além disso, não foi desenvolvida educação ambiental para mobilizar e sensibilizar a sociedade a respeito da discussão das águas do estado, da negociação das metas de qualidade dos recursos hídricos e da importância da efetivação do PERH.

\section{Planos de Bacia Hidrográfica}

Os Planos de Bacia Hidrográfica (PBHs) têm o objetivo de efetivar o processo de planejamento, essencial para que se estabeleçam os usos futuros das águas das bacias hidrográficas (BHs). Com eles, é possível determinar ações para o uso adequado das águas, visando a sua preservação, processo esse de suma relevância para a implementação dos demais instrumentos de planejamento, de gestão e estratégico. A necessidade da sua criação é reivindicada pelos Comitês de Bacias Hidrográficas (CBHs) e pelo Departamento Estadual de Recursos Hídricos (DRH), tendo em vista a importância desse instrumento de planejamento para a consolidação da gestão e do gerenciamento das águas (Paim, 2010) e para garantir a sustentabilidade dos demais recursos naturais na $\mathrm{BH}$.

Os órgãos responsáveis pela elaboração dos planos de BH são as Agências de Região Hidrográfica (ARHs), mas, por causa de sua não consolidação no estado, ${ }^{3}$ os CBHs estão contratando empresas de engenharia para desempenhar tal função. O DRH é responsável por disponibilizar aos CBHs os Termos de Referência (TR) para a elaboração dos PBHs, que são documentos que orientam a implementação desses planos. A elaboração dos $\mathrm{PBHs}$ é realizada em três fases: A) diagnóstico e prognóstico da situação das águas da BH; B) enquadramento das águas em classes de uso; C) elaboração do plano de ações estruturais e não estruturais na $\mathrm{BH}$, para atingir as metas propostas no PBH. Destaca-se que o DRH está elaborando atualmente os Termos de Referência para todas as bacias hidrográficas do estado, para que iniciem os seus respectivos $\mathrm{PBH}$ (Paim, 2010). Mas o DRH passa por entraves no desenvolvimento dessa atividade, dada a falta de técnicos e recursos financeiros, o que dificulta o processo de consolidação do gerenciamento das águas no Estado (Paim, 2010). Na Figura 2 pode-se identificar a realidade das BHs do estado do Rio Grande do Sul quanto à elaboração de seus planos de $\mathrm{BH}$. 


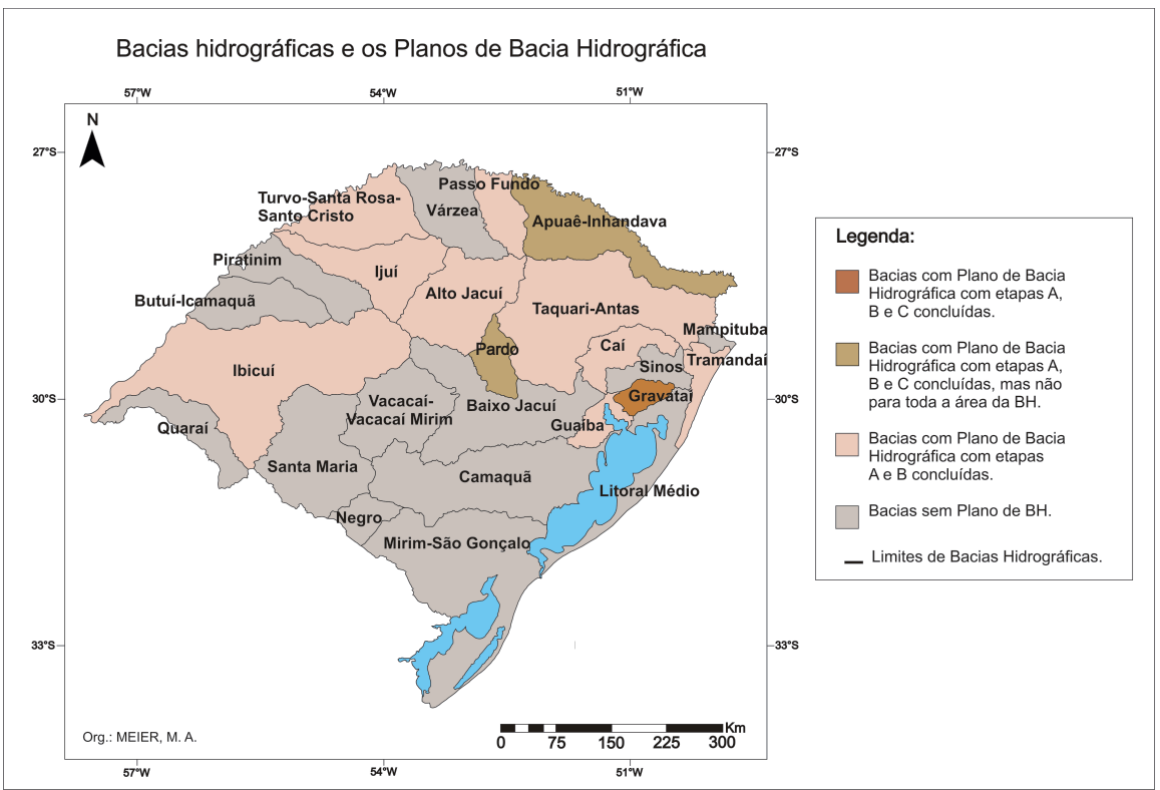

Figura 2 - Comitês de Bacias Hidrográficas e os Planos de BH no Rio Grande do Sul, conforme dados do primeiro semestre de 2013

Fonte: Elaborada pela autora.

No estado do Rio Grande do Sul, apenas uma BH (4\%) possui todas as fases do plano consolidadas para toda a bacia; duas (8\%) têm seu plano de $\mathrm{BH}$ com todas as fases consolidadas, mas para apenas uma parte da bacia; nove (36\%) possuem as fases A e B consolidadas para toda a bacia; 13 (52\%) encontram-se em processo de espera de Termos de Referência ou estão em processo de discussão de seus planos. Em comparação com 2011, ano em que nenhum PBH estava com todas as fases consolidadas para toda a área da bacia - havia dois (8\%) planos com todas as fases consolidadas, mas para apenas parte da $\mathrm{BH}$, e três (12\%) com as fases $\mathrm{A}$ e B consolidada para toda a BH (Meier, 2011) -, verifica-se um avanço na efetivação desse instrumento de planejamento, mas ainda há muito a ser feito para sua implementação efetiva em todo o estado.

Existem muitos entraves para a consolidação dos PBH: falta de discussão da fase $\mathrm{C}$ do plano, o que dificulta a definição das ações para a consolidação das metas propostas no plano; ampla parcela dos planos, já 
discutidos ou em discussão, não tem definidas as suas diretrizes de outorga e cobrança, o que dificulta a efetivação dos instrumentos de gestão na prática. A falta do SEIRH e a pequena ou inexistente fonte de informações e de estações de monitoramento da quali-quantidade das águas nas BHs dificultam a obtenção de informações para o processo de planejamento. Além disso, o estado não possui suas Agências de Região Hidrográfica (ARH) consolidadas efetivamente, ressaltando-se que são elas as responsáveis pela implementação dos $\mathrm{PBHs}$ e pelo auxílio aos CBHs, como braço executivo. Por isso, faz-se necessária a contratação de empresas para a efetivação dos planos, o que traz ônus econômico ao SERH.

Observa-se que, no Rio Grande do Sul, pouco se fez a respeito da implementação dos PBHs, o que gera problemas e atraso na efetivação da legislação dos recursos hídricos no estado, pois eles são documentos importantes para o planejamento das ações sobre a $\mathrm{BH}$ e fundamentais para a implantação dos demais instrumentos.

\section{Enquadramento das águas, segundo classes de uso}

O enquadramento dos corpos hídricos é um estudo para estabelecer as classes de qualidade da água, processo que deve se desenvolver com a participação da sociedade, que irá expor sua opinião sobre os usos futuros dos mananciais, influenciando, portanto, no estabelecimento de metas.

O estudo que estabelece esse enquadramento é considerado parte necessária do planejamento dos demais instrumentos da legislação Plano Estadual e de Bacia Hidrográfica; outorga; cobrança e sistemas de informações - sendo considerado uma das bases para os demais. No estado do Rio Grande do Sul, verifica-se que os Comitês de Bacia Hidrográfica que estão elaborando seus PBHs têm o enquadramento como uma de suas fases (B). A definição da classe de qualidade da água antecede a proposição das ações estruturais e não estruturais do PBH, que objetiva atender às metas propostas pelo enquadramento. Existem também algumas BHs que possuem somente o enquadramento, sendo este desvinculado do PBH (Paim, 2010; Silva, 2011). As BHs que já possuem seu enquadramento podem ser visualizadas na Figura 3.

Observa-se que o Rio Grande do Sul possui 56\% de suas BHs com enquadramento concluído. Se comparado com o ano de 2011, quando apenas $32 \%$ das BHs o possuíam (Meier, 2011), observa-se um significativo 
aumento na implementação desse instrumento, mas ainda há muito a ser feito em todo o estado.

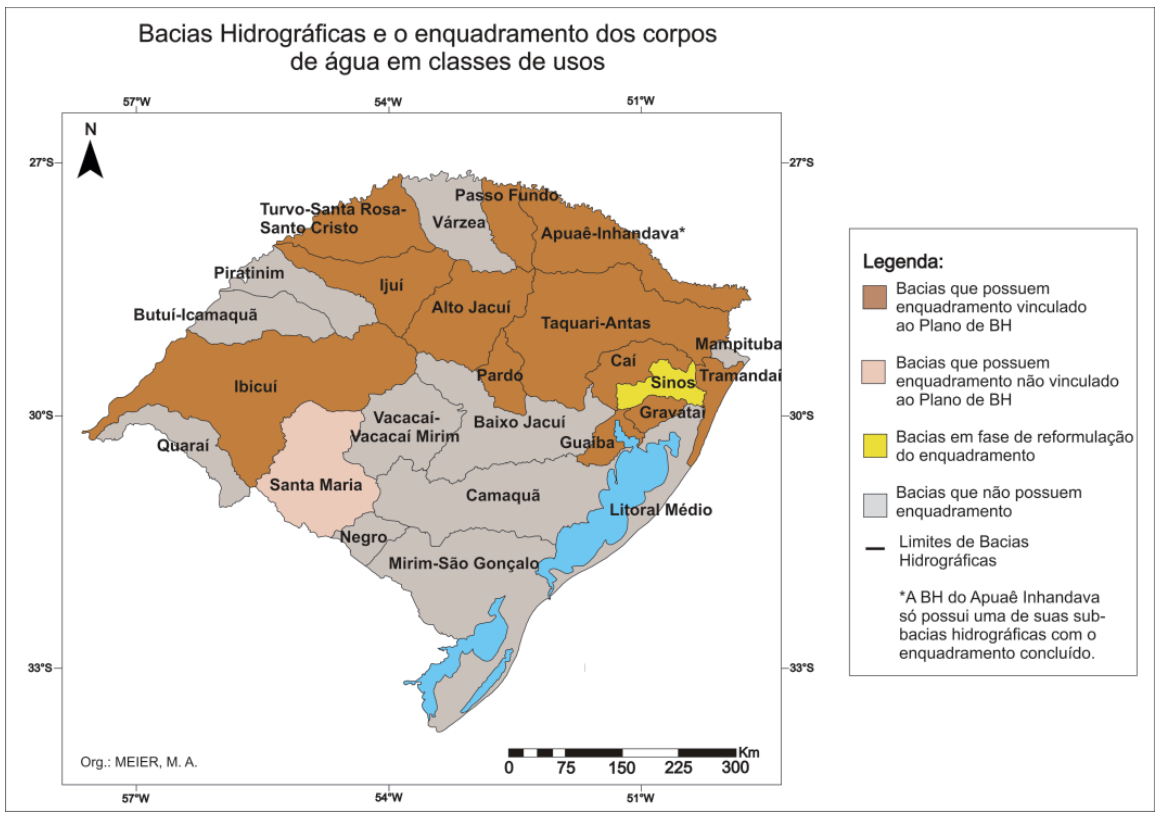

Figura 3 - Enquadramento dos corpos de água em classes de uso. ${ }^{4}$

Fonte: Elaborada pela autora.

Entre os entraves para a efetivação dos enquadramentos no estado elenca-se a falta dos planos de $\mathrm{BH}$, dos quais o enquadramento é uma das etapas. Além disso, os planos que se consolidaram sem a fase $C$ não possuem ações que possam contribuir para que o enquadramento seja atingido. O desconhecimento do SERH pela população dificultou a ativa participação desta no processo de consolidação do enquadramento. Por outro lado, a falta de um sistema de monitoramento das águas não permite observar se o enquadramento vem sendo atingido ou não. E o enquadramento encontra-se desvinculado dos instrumentos de gestão, por causa de sua falta em expressivo número de $\mathrm{BH}$ no estado e à não sistematização do SEIRH, que possibilita um fluxo de informações entre ambos. Os instrumentos de gestão necessitam estar embasados nos instrumentos de 
planejamento, pois devem garantir que as metas para a $\mathrm{BH}$ (construídas a partir dos instrumentos de planejamento) sejam atingidas.

\section{Outorga das águas}

A outorga é uma autorização para a retirada de água de corpo hídrico, superficial ou subterrâneo, ou para o lançamento de efluentes. Tem a finalidade de fazer uma repartição equitativa da água entre os usuários (Rio Grande do Sul, 1994). Para que a outorga se efetive, é necessário que as instâncias responsáveis por sua implementação possuam o conhecimento referente às características dos recursos hídricos da $\mathrm{BH}$ em que a outorga será expedida. Esses dados referem-se: à quantidade e à qualidade de água que determinado corpo hídrico possui; às metas de qualidade do enquadramento a serem alcançadas; à quantidade de água necessária ao corpo hídrico, para que se mantenha a vida dos ecossistemas aquáticos. A partir desses dados é possível estipular a quantidade de água outorgável do corpo hídrico. Na sequência analisam-se a demanda dos usuários e as regras de repartição das águas da BH, para então desenvolver uma divisão delas de maneira igualitária.

É imprescindível o estabelecimento de regras claras sobre a repartição das águas. Essas regras devem estar presentes nos planos de $\mathrm{BH}$ e serem negociadas com a população e usuários da BH (Rio Grande do Sul, 1994). As informações sobre os recursos hídricos da BH, no que diz respeito às regras de repartição, devem estar acessíveis aos órgãos responsáveis pela expedição das outorgas, que, no caso do Rio Grande do Sul, são o DRH (outorgas quantitativas) e a Fepam (outorgas qualitativas). Isso é possível mediante o estabelecimento de um sistema de informações organizado e de fácil acesso.

No Rio Grande do Sul, a outorga vem sendo expedida desde o ano de 1999, sendo esse o primeiro instrumento de gestão a avançar no estado. Na sequência, a constituição dos $\mathrm{CBHs}$ obteve destaque, e atualmente há ênfase na implementação dos PBHs e no desenvolvimento do SEIRH (Silva, 2011).

A outorga das águas está implementada em todo o estado e é realizada pela Secretaria Estadual do Meio Ambiente (Sema). Ocorre de duas maneiras: efetivamente, como instrumento de gestão, e de maneira cartorial. Para que a outorga não seja cartorial, é necessário que haja o conhe- 
cimento da disponibilidade, da demanda e dos critérios de repartição das águas, constituindo uma base segura para a tomada de decisão quanto à sua emissão (Paim, 2010).

A outorga cartorial é expedida mediante autorização e concessão de uso, sem o conhecimento das características da disponibilidade e demanda da água na $\mathrm{BH}$, e não possui critérios predefinidos para a sua expedição. A falta dessas informações e a complexidade em obtê-las geram um entrave para a efetivação das licenças de uso, que seriam os efetivos instrumentos de gestão (Silva, 2011).

Os entraves que dificultam a obtenção dessas bases para a outorga centram-se na falta ou na conclusão parcial dos planos de $\mathrm{BH}$, que devem disponibilizar as informações sobre a qualidade, quantidade e regras de repartição das águas para a outorga; na ausência de enquadramento das águas da $\mathrm{BH}$, que deve estipular metas de qualidade futura das águas, devendo a outorga colaborar com o seu alcance; e na necessidade de implementação do SEIRH, para que possa disponibilizar as informações necessárias à outorga e sobre os processos de outorga, possibilitando o uso das regras já estabelecidas, além de agilizar o seu processo de expedição e consulta.

Percebe-se que a outorga depende dos instrumentos de planejamento e estratégico, para que possa ser um verdadeiro instrumento de gestão. Por sua vez, a outorga influi na efetivação da cobrança, pois propicia informações e uma base técnica para sua implementação. Além disso, a outorga proporciona o alcance dos objetivos de qualidade previstos nos instrumentos de planejamento, contribuindo para a sustentabilidade do uso dos recursos hídricos. Na Figura 4 a seguir podem-se observar as BHs que possuem outorga da água.

Observa-se que 28\% das BHs possuem critérios de outorga definidos com base nas informações da $\mathrm{BH}$, três delas vinculadas aos instrumentos de planejamento da BH (Apuaê-Inhandava, Pardo e Gravataí), duas desvinculadas desses instrumentos (Santa Maria e Sinos) e duas com os critérios vinculados aos seus instrumentos de planejamento, que se encontram parcialmente constituídos (Ibicuí e Alto Jacuí). Setenta e dois por cento das BHs não estruturaram suas regras para a outorga, sendo esse um reflexo da falta ou da implementação parcial dos instrumentos de planejamento no estado. 


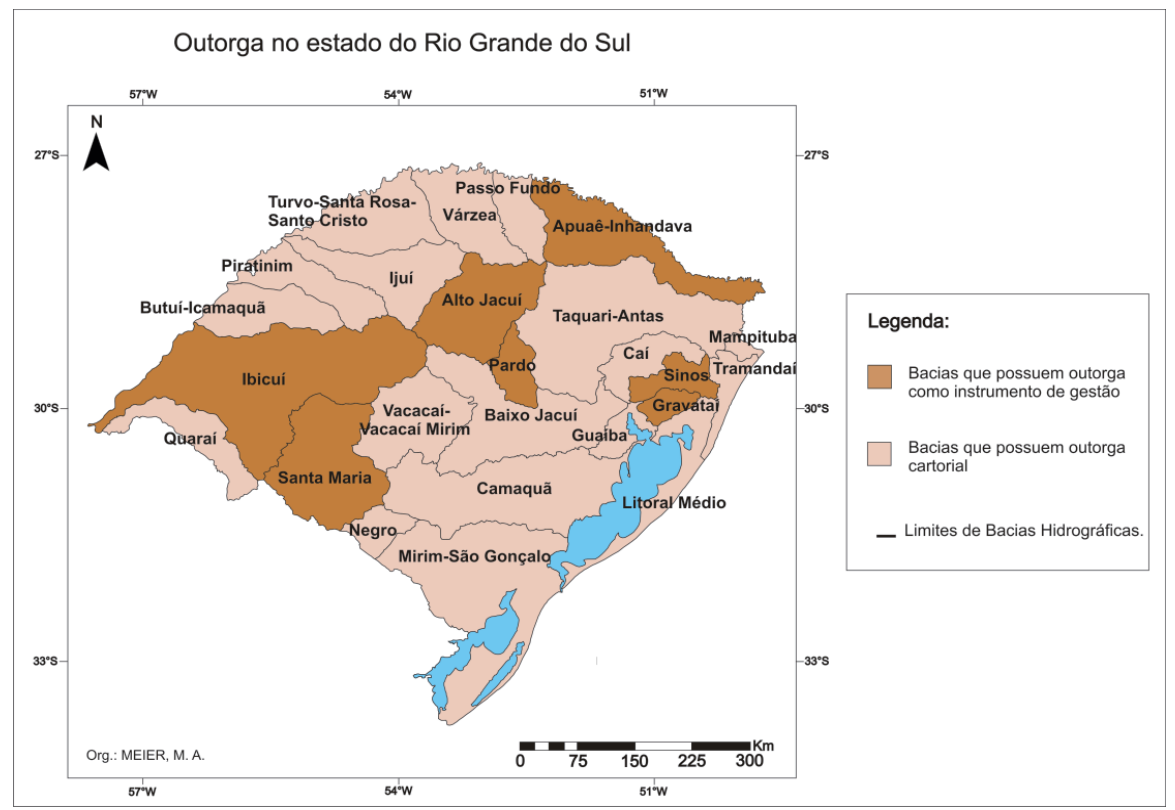

Figura 4 - Outorga da água no Rio Grande do Sul, no primeiro semestre de 2013 Fonte: Elaborada pela autora.

Cobrança das águas

A cobrança sobre o uso da água deverá ser realizada para a captação de recursos hídricos tanto superficiais quanto subterrâneos e terá como objetivo minimizar os desperdícios, visando o seu uso racional, preservando e mantendo a qualidade das condições locais. Busca também subsidiar financeiramente o programa de ações previsto nos PBHs, sendo seus valores aplicados na própria bacia (Rio Grande do Sul, 1994).

As BHs dos rios Pardo, Apuaê Inhandava, Alto Jacuí e Guaíba possuem diretrizes estruturadas para a cobrança vinculadas à discussão de seus instrumentos de planejamento, mas ainda não foram postas em prática (Figura 5). As BHs dos rios Ibicuí e Santa Maria estabeleceram apenas propostas e estudos de viabilidade da cobrança das águas. E os demais CBHs ainda não possuem critérios estabelecidos para a cobrança das águas. 


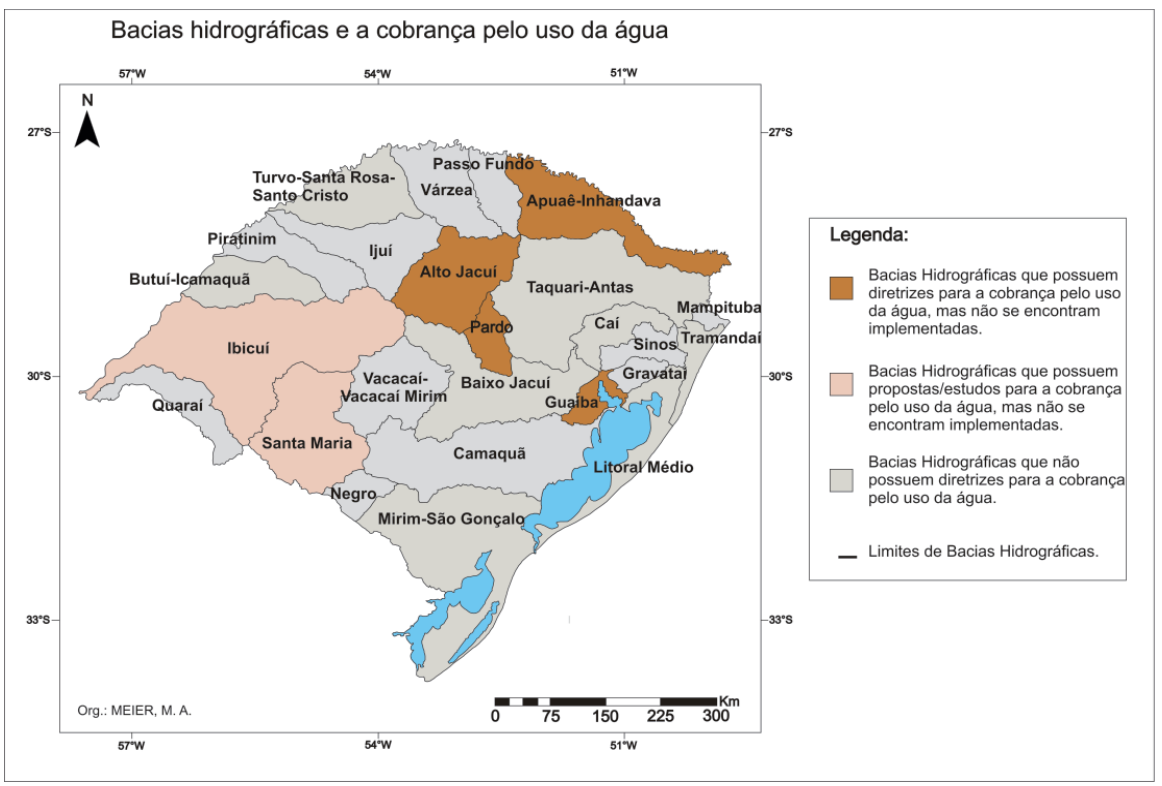

Figura 5 - BHs que possuíam propostas de cobrança pelo uso da água no Rio Grande do Sul, no primeiro semestre de 2013 Fonte: Elaborada pela autora.

A cobrança pelo uso da água é de suma importância para o processo de gerenciamento dos recursos hídricos no estado, pois auxilia na obtenção do autossustento financeiro do SERH e dos CBHs, além de financiar o Plano de Ações estabelecido nos PBHs. Para que a cobrança se consolide é necessário haver uma estrutura anteriormente estabelecida, sendo esse um dos principais entraves e motivos para a sua não implementação no estado.

Entre os aspectos que impossibilitam implementar a cobrança da água tem-se a não constituição do SERH quando há a falta das ARHs, órgãos que possuem como atribuições arrecadar e destinar os recursos captados pela cobrança de acordo com os PBHs. Além disso, muitas bacias não estruturaram suas diretrizes de cobrança, em função da falta dos demais instrumentos, principalmente os de planejamento, que fornecem as diretrizes para essa cobrança, os valores a ser cobrados, o destino dos valores arrecadados, as informações de disponibilidade e a demanda real 
das águas. Esses instrumentos ainda estão em discussão no estado atualmente (Paim, 2010).

Tem-se ainda a necessidade da implementação de uma outorga de fato no Rio Grande do Sul, que possua uma base sólida de informações referentes à disponibilidade e à demanda de água dentro da $\mathrm{BH}$, além de critérios claros para sua implementação. Só assim seria possível atingir o objetivo de a outorga se efetivar como um verdadeiro instrumento de gestão. Diante disso, será possível desenvolver um instrumento de cobrança embasado na real demanda de água, estabelecendo critérios adequados, impossibilitando que seja injusta ou que não atinja aos objetivos propostos, que visa a racionalizar o uso das águas (Silva, 2011).

Como entraves, destaca-se ainda a divergência de interesses quanto aos valores e destino dos recursos financeiros, que necessitam de ampla discussão com a sociedade. Somam-se a isso a burocracia na tomada de decisões e a falta de apoio aos CBHs na efetivação da cobrança pelo uso da água.

Entre as perspectivas para a implementação da cobrança, destaca-se a necessidade de todos os instrumentos estarem consolidados para balizar a cobrança: PERH, PBH, enquadramento, SEIRH e outorga. Há, ainda, a necessidade de criação das ARHs para arrecadar e destinar adequadamente os valores recolhidos, e de desenvolvimento de educação ambiental significativa para que a sociedade compreenda a real importância da cobrança pelo uso da água, para que possa discuti-la nos CBHs.

Vale destacar que a cobrança poderá vir a surgir antes de essa estrutura estar pronta, mas poderá ocorrer de maneira inadequada, deixando margem para que não atinja os objetivos estipulados na legislação, pois "sem isso a cobrança pode ser até injusta, elaborar critérios em base de informações que não são muito adequadas”, conforme afirma Silva, em entrevista concedida à autora em 2011.

\section{Sistema Estadual de Informações sobre os Recursos Hídricos}

O Sistema Estadual de Informações sobre os Recursos Hídricos (SEIRH) objetiva coletar, tratar, armazenar e recuperar informações sobre os recursos hídricos e questões que se relacionem com a sua gestão. Isso agilizaria a tomada de decisões sobre os recursos hídricos, garantindo o direito que a sociedade tem de obter informações referentes a eles, para atuar efetivamente na gestão das águas nas BHs (Brasil, 1997). 
Na legislação estadual de recursos hídricos, o SEIRH não é claramente elencado como instrumento, mas, devido à sua relevância e por ser considerado um instrumento na legislação nacional de recursos hídricos, deve ser implementado no estado do Rio Grande do Sul.

A necessidade de implementação do SEIRH surgiu por uma demanda vinda de vários órgãos ligados ao SERH, durante o processo de implementação dos demais instrumentos de recursos hídricos. Esses órgãos, na discussão dos instrumentos, perceberam a falta de uma base de dados e um instrumento que pudesse agilizar e automatizar a obtenção de informações sobre as águas nas BHs (Silva, 2011). Isso ocorre porque os demais instrumentos fornecem informações e ao mesmo tempo necessitam das informações do SEIRH para se consolidar (Paim, 2010).

Nos últimos cinco anos verificou-se o destaque para a implementação do SEIRH no estado do RS, estando em pleno desenvolvimento. É responsabilidade do DRH sua implementação, tendo um convênio com a Procergs ${ }^{5}$ que auxilia nas soluções de tecnologia da informação (Silva, 2011).

O início formal dos trabalhos de construção do SEIRH ocorreu no ano de 2008, e ao longo do processo de sua consolidação teve colaboração dos demais órgãos do SERH, mediante a disponibilização de informações e discussão da estruturação desse instrumento (Silva, 2011).

A estrutura/arquitetura do SEIRH seguiu na mesma lógica do Sistema de Informações de Recursos Hídricos Nacional (SNIRH), ${ }^{6}$ com o objetivo de compatibilizar e articular os sistemas de informações de recursos hídricos. As principais fontes de informação que virão a alimentar o SEIRH serão provenientes: do cadastro de usuários da água (via online); do SIG, para espacialização das informações sobre os recursos hídricos; da rede de monitoramento hidrometerológico; da compilação e disponibilização de informações provenientes dos planos, destacando-se as características das BHs, os critérios de outorga, a cobrança e as metas de enquadramento; e do cadastro de outorgas, entre outras informações disponíveis sobre os recursos hídricos. As informações que estiverem dentro do sistema de informações possuirão um módulo que possibilitará a geração de relatórios-síntese, a partir do cruzamento das informações disponíveis. Esses relatórios agilizarão e automatizarão a atuação do DRH na tomada de decisões e a atuação dos CBHs, além de proporcionar à população uma visão mais abrangente das condições da BH onde residem (Silva, 2011). 
Entre os módulos já implementados no SEIRH destaca-se o Cadastro de Usuários da Água ${ }^{7}$ e a formulação de um esboço de SIG, e está em processo de planejamento o cadastro de outorgas, que atualmente está apenas sendo realizado de maneira analógica e disponibilizado em formato de planilhas. Posteriormente o cadastro de outorgas será disponibilizado online (com plataforma própria e de atualização automática), divulgando não apenas as outorgas expedidas, mas também todo o seu processo de tramitação. A inteligência hídrica, a modelagem hídrica e o sistema de monitoramento da qualiquantidade das águas, por $\mathrm{BH}$ e por trechos de rios, ainda não foram estruturados (Silva, 2011).

Com a implementação do SEIRH será possível contribuir para a implementação dos demais instrumentos, pois facilitará a obtenção de dados e informações que servirão de base, e para a agilização na tomada de decisão sobre os recursos hídricos por parte dos técnicos responsáveis. Permitirá também a articulação dos instrumentos de planejamento com os de gestão, mediante fluxo de informações entre eles. Nesse sentido, o planejamento da BH é realizado e utilizado na efetivação da outorga, da cobrança, nas atividades de licenciamento ambiental e nas demais formas de tomada de decisões e intervenções diretas sobre o uso das águas nas BHs.

Com o SEIRH, os cidadãos poderão obter facilmente as mais diversas informações sobre as BHs, potencializando as ações de educação ambiental com a população. Assim contribuirá com a compreensão da realidade em que os cidadãos estão inseridos, proporcionando uma atuação efetiva e consciente nas decisões sobre os recursos hídricos.

\section{Considerações finais}

Em todo o território nacional há uma necessidade eminente de se desenvolver uma gestão e um gerenciamento eficazes dos recursos hídricos, devido a sua degradação qualitativa e quantitativa. A legislação possui premissas inovadoras que garantem a preservação das águas, criando a Política Nacional e a Estadual de Recursos Hídricos que instituem os Sistemas Federal e Estadual de Recursos Hídricos. Esses sistemas são compostos por diversos órgãos, cada qual com suas atribuições, responsáveis por instituir os instrumentos que são os indicadores da gestão e gerenciamento das águas tanto em âmbito nacional quanto estadual. No estado do Rrio Grande do Sul, a conjuntura atual dos instrumentos da 
Política Estadual de Recursos Hídricos pode ser sintetizada como apresentado no Quadro a seguir.

Quadro - Quadro-síntese da conjuntura atual dos Instrumentos da Política Estadual de Recursos Hídricos do Estado do Rio Grande do Sul

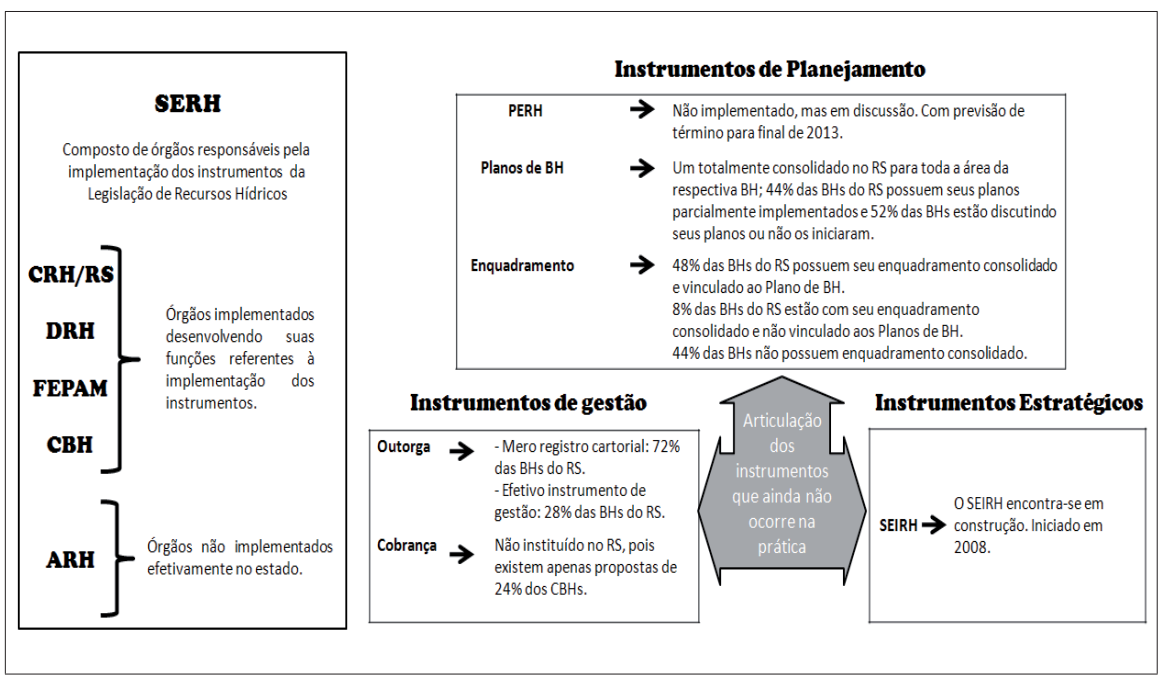

Fonte: Organizado pela autora.

Entre as perspectivas ao gerenciamento no estado está o incentivo atual na formulação e conclusão do PERH e dos planos de BH, sendo conjuntamente consolidado o enquadramento. A efetivação dos instrumentos de planejamento possibilitará a construção das bases da outorga e da cobrança, podendo essas se efetivar na prática como verdadeiros instrumentos de gestão dos recursos hídricos. Verifica-se também um esforço na consolidação do SEIRH para sistematizar as informações e agilizar a sua disponibilização aos diversos órgãos do SERH, como também para a sociedade.

Quando o SERH e os instrumentos se consolidarem, mediante ativa participação da sociedade e sua verdadeira representatividade, será possível efetivar a legislação de recursos hídricos no estado. Desse modo, construindo um processo verdadeiro de retirada da desigualdade e da consolidação plena da democracia e da cidadania da população, possibilita-se a obtenção de água em condições de qualidade e quantidade adequadas à garantia de melhor qualidade de vida. 
Nesse contexto, pode-se verificar que o estado do RS, mesmo sendo um dos pioneiros na questão das discussões dos recursos hídricos, ainda passa por desafios e entraves na execução e efetivação da legislação dos recursos hídricos e várias são as questões a avançar e discutir.

\section{Notas}

1. Dissertação de mestrado financiada pela Coordenação de Aperfeiçoamento de Pessoal de Nível Superior (CAPES), mediante bolsa de mestrado que teve vigência de março de 2010 a março de 2011.

2. No estado, nesse período, apenas três BHs possuíam o Plano de BH parcialmente constituído.

3. No estado existe atualmente uma proposta de implementação de ARH. A Fundação Estadual de Planejamento Metropolitano e Regional (Metroplan) está assumindo provisoriamente a função de ARH, para possivelmente tornarse definitivamente a ARH do Guaíba.

4. Dados referentes ao primeiro semestre de 2013.

5. Companhia de Processamento de Dados do Estado do Rio Grande do Sul.

6. Na página da Agência Nacional de Águas (ANA) está disponível o SNIRH para consultas: <http://www.ana.gov.br/portalsnirh/.>.

7. O cadastro de usuários da água (Ceusa) está contido na plataforma de Informação, Cidadania e Ambiente (ICA), hospedada no site da Sema: <http://www. sema.rs.gov.br/>. O Ceusa apenas coleta informações, sem disponibilizá-las ao público.

\section{Referências}

BRASIL. Lei n. 9.433, de 8 de janeiro de 1997. Institui a Política Nacional de Recursos Hídricos. Disponível em: <http://www2.planalto.gov.br/>. Acesso em: 20 dez. 2012.

LEAL, A. C. Gestão das águas no Pontal do Paranapanema. Tese (Doutorado em Geociências). Universidade Estadual de Campinas, Campinas, SP, 2000.

MEIER, M. A. A conjuntura dos instrumentos da Política Estadual de Recursos Hídricos do estado do Rio Grande do Sul. Dissertação (Mestrado em Geografia). Universidade Federal de Santa Maria, Santa Maria, RS, 2011.

PAIM, P. Paulo Paim: Entrevista [jul. 2010]. Entrevistador: M. A. Meier. Porto Alegre: DRH-RS, 2010. 1 cd sonoro. Entrevista concedida ao projeto "A conjuntura dos instrumentos de gestão da Legislação dos Recursos Hídricos no Estado do Rio Grande do Sul".

PORTO, M. F. A.; LOBATO, F. Mechanisms of Water Management: Economics Instruments and Voluntary Adherence Mechanisms. Revista de Gestion Del'Agua de America Latina, v. 1, p. 132-46, 2004a. 
; ______. Mechanisms of Water Management: Command \& Control and Social Mechanisms. Revista de Gestion Del'Agua de America Latina, v. 2, p. 11329, $2004 b$.

; PORTO, R. L. L. Gestão de bacias hidrográficas. Estudos Avançados, v. 22, p. 43-60, 2008.

RIO GRANDE DO SUL. Política Estadual de Recursos Hídricos. Lei n. 10.350, de 30 de dezembro de 1994. Disponível em: <http://www.al.rs.gov.br/site/>. Acesso em: 20 out. 2009.

- Departamento de Recursos Hídricos do Estado do Rio Grande do Sul (D. $\overline{\mathrm{R}} \mathrm{H})$. Relatório anual sobre a situação dos recursos hídricos no estado do Rio Grande do Sul. Edição 2007/2008. Porto Alegre: DRH, 2008.

SILVA, J. M. T. da. João Manuel Trindade da Silva: Entrevista [abr. 2011]. Entrevistador: M. A. Meier. Porto Alegre: DRH-RS, 2011. 1 CD sonoro. Entrevista concedida ao projeto "A conjuntura dos instrumentos de gestão da Legislação dos Recursos Hídricos no Estado do Rio Grande do Sul”.

VICTORINO, C. J. A. Planeta água morrendo de sede: uma visão analítica na metodologia do uso e abuso dos recursos hídricos. Porto Alegre: Edipucrs, 2007.

Mara Alini Meier - Possui graduação em Geografia pela Universidade Federal de Santa Maria. Mestrado em Geografia pelo Curso de Pós-graduação em Geografia e Geociências pela mesma Universidade. Atualmente é Doutoranda do Curso de Geografia da Universidade Federal do Rio Grande do Sul. 